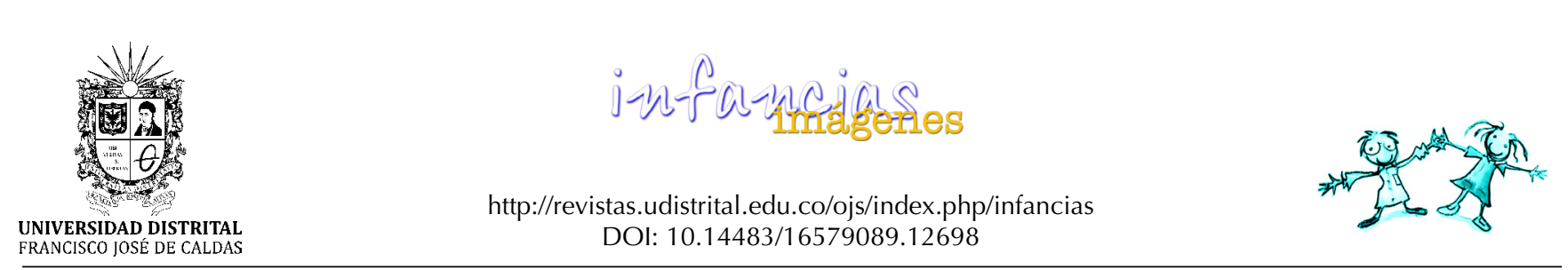

IMÁGENES DE INVESTIGACIÓN

\title{
El hábitat urbano informal y los derechos de la infancia en Bogotá* $^{*}$
}

\author{
The Informal Urban Habitat and the Rights of Children in Bogota \\ Olga Lucía Ceballos Ramos ${ }^{1}$
}

Para citar este artícullo: : Ceballos, O. L. (2018). El hábitat

Recibido: 22-noviembre-2017 / Aprobado: 19-marzo-2018

urbano informal y los derechos de la infancia en Bogotá.

Infancias Imágenes, 17(1), 38-52.

\section{Resumen}

En este artículo se exponen las reflexiones basadas en los resultados de la investigación sobre la relación entre el disfrute de los derechos de la infancia y el hábitat. En esta se abordó lo referido a la vulneración de derechos fundamentales de los niños, niñas y adolescentes (NNA) en Colombia. Se explora el tema en el barrio Potosí, en Bogotá, de origen informal, del cual se presenta lo expresado por niños y niñas, así como de madres, lideresas comunitarias y docentes. La información se contrasta con lo hallado en la literatura sobre la materia de interés, haciendo énfasis en los derechos enunciados en el artículo 44 de la Constitución Política de Colombia de 1991. Este análisis permitió concluir que existe una relación entre las condiciones del hábitat y la vulneración de los derechos fundamentales de NNA cuando dichas condiciones son deficitarias tanto en la escala urbana como en la arquitectónica.

\begin{abstract}
This article presents reflections based on the results of research on the relationship between the enjoyment of children's rights and habitat. This addressed the violation of fundamental rights of children and Adolescents (NNA) in Colombia. The topic is explored in the neighborhood Potosí, in Bogotá, of informal origin, which is presented by children, as well as mothers, community leaders and teachers. The information is contrasted with what was found in the literature on the matter of interest, emphasizing the rights set forth in article 44 of the Colombian Political Constitution of 1991. This analysis made it possible to conclude that there is a relationship between the conditions of the habitat and the violation of the fundamental rights of NNA when these conditions are deficit both in the urban and in the architectural scale.
\end{abstract}

Keywords: rights; childhood; poverty; habitat.

Palabras clave: derechos; infancia; pobreza; hábitat.

\footnotetext{
* Artículo resultado de la investigación "Infancias y ciudades. Una lectura desde las formas de habitar el territorio en Bogotá", financiada por la Pontificia Universidad Javeriana de Bogotá y realizada entre febrero de 2014 y julio de 2017.

1 Magíster en Urbanismo y Arquitecta, Universidad Nacional de Colombia. Profesora asociada, Facultad de Arquitectura y Diseño, Pontificia Universidad Javeriana. Directora editorial de la revista Cuadernos de Vivienda y Urbanismo. Correo electrónico: olga.ceballos@javeriana.edu.co
} 


\section{Introducción}

En la Asamblea General de las Naciones Unidas de 1959 fue adoptado el decálogo de los derechos de los niños, niñas y adolescentes (NNA). Pero, es a partir de la Convención de los Derechos del Niño de 1989 cuando se consagra la prevalencia de la doctrina de la protección integral de manera diferente a la doctrina de la situación irregular. Se pasa, entonces, de considerar a los NNA como objeto de protección del Estado, de la sociedad y de la familia a su reconocimiento como sujetos de derecho (Campos, 2009). Con la promulgación de la Constitución Política de la República de Colombia en 1991 se dio un importante cambio en la acepción tanto del Estado como de los derechos ciudadanos. Es mediante esta carta política que se reconoce al Estado como de derecho, democrático y social. Sobre lo primero, se le confiere la obligación de respetar los derechos y libertades de sus ciudadanos. Respecto a lo segundo, se establece que los titulares del poder político deben someterse a elección popular y que es el pueblo el que tiene derecho a decidir sobre los asuntos que afecten a la comunidad. Sobre lo último, que el Estado tiene la obligación de garantizar condiciones de vida dignas para todos sus ciudadanos (Jaramillo, 2007). Así, en el artículo 44 se reconocen los derechos de los NNA con un carácter de prevalencia, reglamentado en el Código de Infancia y Adolescencia mediante la Ley 1098 de 2006; en este se posiciona a NNA como sujetos de derechos en la legislación y sociedad colombiana. A su vez, postula como objetivo que los NNA crezcan en el núcleo familiar y comunitario; es decir, en entornos que estén caracterizados por factores protectores, con reconocimiento de su derecho a la igualdad y la dignidad humana y sin discriminación alguna. De igual manera, reivindica los principios de protección integral, interés superior, prevalencia de los derechos y corresponsabilidad para el ejercicio, goce, garantía, protección y restablecimiento de los derechos de los NNA (Cely, 2015).

No obstante, el disfrute pleno de los derechos de los NNA está mediado por diversos factores sociales, económicos y ambientales. Al respecto, en este artículo se exponen los resultados de un estudio exploratorio de tipo cualitativo sobre la incidencia de las condiciones del hábitat en el disfrute pleno de los derechos de la infancia, haciendo énfasis en primera infancia e infancia. El análisis se centra en las condiciones del hábitat presentes en los asentamientos urbanos de origen informal en la ciudad de Bogotá y su relación con el disfrute por parte de los NNA de los derechos que les han sido reconocidos desde la Convención de 1989, según sus cuatro principios fundamentales (Naciones Unidas, 2002):

1. La no-discriminación (artículo 2).

2. El interés superior de los NNA (artículo 3).

3. El derecho de los NNA a la vida, la supervivencia y el desarrollo (artículo 6).

4. El respeto por las opiniones de los NNA (artículo 12).

\section{Infancia y hábitat}

En la literatura reciente relacionada con el estudio de las infancias en contextos urbanos se tiende a privilegiar la reflexión sobre los derechos de los NNA por encima de su participación sobre las decisiones en la ciudad. Para Francesco Tonucci, la ciudad moderna ha olvidado a los niños para privilegiar a los adultos y a los automóviles. Por lo tanto, se les niega uno de sus derechos fundamentales como lo es el derecho al juego (artículo 31 de la Convención de los Derechos del Niño); así como a la movilidad con autonomía, dado que la calle y en general el espacio público se ha convertido en un lugar considerado por los adultos como peligroso. Al respecto, señala Tonucci la manera en que el urbanismo se ha ocupado de definir espacios controlados en la ciudad para los niños a los cuales sus padres o cuidadores puedan llevarlos, en lugar de generar condiciones para que puedan disfrutar del encuentro y el juego con sus pares de manera autónoma en el espacio público. Al ser contrario a lo postulado en los derechos de la infancia, Tonucci reivindica el derecho que tienen los niños y niñas a participar de las decisiones que se tomen en su ciudad, así como la necesidad de adelantar acciones al respecto (Tonucci, 2005).

En cuanto a la participación de los NNA en las decisiones que les afectan, reconocido como derecho y uno de los pilares de lo estipulado por la Convención de los Derechos del Niño, constituye 
para Roger Hart un indicador del nivel real de la democracia de una nación. En consecuencia, Hart propone lo que ha denominado la escalera de participación como una metáfora para reflexionar sobre el verdadero rol y la importancia que se le reconoce a la opinión de los NNA en los procesos de participación. Plantea entonces un rol activo de los NNA en diferentes momentos, edades, escenarios y crecimiento en la práctica de la participación, a partir de lo cual la participación infantil es dinámica, circular, flexible y adaptable al contexto (Hart, 1993). Los planteamientos de Tonucci y Hart se han erigido en buena medida como base del programa Ciudades Amigas de la Infancia, iniciativa que desde 1996 se ha propuesto la defensa de los derechos de la infancia considerados en la Convención de $1989^{2}$.

No obstante, aún persisten dificultades para el disfrute pleno de los derechos de los NNA en la ciudad. Como señala Sanz:

La redistribución de bienes no favorece al niño. Si los derechos del niño entran en conflicto con los de los adultos, apenas hay debate: las medidas políticas urbanas se toman favoreciendo al segundo. El barrio no se plantea reducir el tráfico y los aparcamientos para hacer un lugar más seguro y habitable para los niños. Por el contrario, cuando se toma una decisión que afecta a la capacidad de hacer efectivos los derechos del niño, como el libre desplazamiento, se prioriza la economía del tiempo y el espacio para los vehículos, aunque suponga un perjuicio en el niño. (2014, p. 50)

En esta dirección, Manu González señala la importancia de la autonomía espacial para los niños y las niñas, pues al limitarla se reduce drásticamente el tiempo disponible para el juego. Por lo anterior, se tiende entonces a imponerse los juegos individuales y pasivos en el hogar bajo la organización

\footnotetext{
2 Esta iniciativa internacional desde 1996 ha velado por el cumplimiento de la resolución aprobada durante la segunda Conferencia de las Naciones Unidas sobre Asentamientos Humanos (Hábitat II), cuyo objetivo era lograr ciudades en las que todos pudieran vivir. En esta conferencia se postuló el bienestar de los niños como indicador definitivo de un hábitat saludable, de una sociedad democrática y de una buena gobernanza (Unicef, 2009).
}

y la supervisión de los adultos (González, 2012). A este respecto, Tuline Gülgönen, y Yolanda Corona coinciden con Sanz y González, pues consideran que la exclusión de los niños en el espacio público denota su expulsión de la comunidad. No solamente se vulnera su derecho al juego, de igual manera su derecho al ejercicio de su ciudadanía. Por ello, las investigadoras enfatizan sobre la importancia de permitir a los niños participar en la planeación urbana y en particular en el diseño de los espacios destinados para su disfrute (Gülgönen y Corona, 2015).

De otro lado, Rubén Kaztman (2011) integra diversas escalas del hábitat para el desarrollo de un análisis de la relación entre las privaciones en las condiciones de habitabilidad y el desarrollo de capital humano. Considerando como hipótesis que el desarrollo del capital humano en la infancia es la vía más importante para desactivar los mecanismos de reproducción inter-generacional de la pobreza, su análisis indaga la incidencia de la calidad de las condiciones habitacionales en los logros educativos de los NNA. Se centra en tres condiciones de la vivienda como son: su tamaño en relación con el tamaño del hogar que la ocupa, materiales de construcción y abastecimiento de agua y desagües; las anteriores, analizadas respecto al nivel mínimo requerido para el cumplimiento de los derechos de la infancia. Así, propone tres factores de control: ingresos, nivel educativo de la madre y hacinamiento en la vivienda, para analizar relaciones causales de la extra edad escolar.

Después de analizar los datos de los 17 países de América Latina, Kaztman concluye que cada uno de los tres factores de control tiene un efecto sobre la extra-edad, independiente de los de los otros dos. Esto indicaría la necesidad de ejecutar políticas que integren estos tres factores para mejorar los logros educativos de los NNA, dado que demuestra que son determinantes y actuar solamente en uno o dos sería insuficiente. Además, Kaztman destaca que el hacinamiento se constituye en un factor asociado a la extra edad escolar aun en casos en los que no hay pobreza. Esto demuestra una incidencia directa e independiente de otros factores de una de las condiciones de habitabilidad en la vulneración del derecho de la infancia a la educación. 
Respecto a las conclusiones de Kaztman, debe señalarse que la situación de vulneración de derechos de la infancia puede ser aún más dramática en los asentamientos urbanos de origen informal, pues las condiciones de habitabilidad suelen estar por debajo del nivel adecuado para garantizar una vida digna (Tarchópulos y Ceballos, 2003)³. Sumado a lo anterior, cabe anotar que la autopercepción de los NNA está mediada por las condiciones de su entorno; como señala Duarte (2013), los niños y las niñas no se ven igual a sí mismos si pertenecen a diferente clase social o condición de vida. En el caso de quienes habitan en asentamientos de origen informal, que generalmente viven en situación de pobreza, los NNA están más expuestos a la violencia o a la separación de sus familias, entre otras problemáticas. Auyero afirma: "los pobres no respiran el mismo aire, no toman la misma agua y no juegan en las mismas zonas de recreación que los demás" (Auyero, 2010, p. 25). Asimismo, los NNA en estos contextos están más expuestos a problemas de insalubridad, violencia y abuso sexual, asociados a las condiciones de hacinamiento generalmente presentes en sus viviendas (Feres y Mancero, 2001; Ceballos, Caicedo, Fernández y Rincón, 2014).

\section{Referencias conceptuales y métodos}

Según lo expuesto, la literatura referida sobre la relación entre los derechos de la infancia y las condiciones de habitabilidad del lugar en donde habita demuestra que efectivamente estas últimas pueden contribuir a la vulneración de los primeros. Sin embargo, aún no se ha profundizado de manera suficiente sobre la situación de los derechos de la infancia que habita en asentamientos de origen informal. En el estudio planteado se propone como premisa que las deficiencias de habitabilidad presentes en los asentamientos de origen informal inciden de manera negativa en el disfrute pleno de los derechos de la infancia. Con esta premisa, se planteó el desarrollo de actividades con población

\footnotetext{
3 Las condiciones deficitarias de habitabilidad presentes en estos asentamientos son atribuibles a la manera en que se desarrollan al margen de las exigencias urbanísticas y de construcción. Esta situación incluso se mantiene aún después de haber sido legalizados, siendo necesario mucho tiempo e inversión para superarla.
}

residente en el barrio Potosí, de origen informal y localizado en Bogotá, conformada por madres de niños y niñas en primera infancia e infancia, lideresas comunitarias, docentes y niños en infancia, para conocer su percepción al respecto. $Y$ a partir de este ejercicio, se analizó dicha percepción respecto a las conclusiones de estudios precedentes y se propusieron hipótesis de trabajo para ser abordadas en la etapa final del estudio.

\section{El barrio Potosí}

En Bogotá, durante las décadas de 1970 y 1980, se desarrollaron numerosos asentamientos informales por gestión de los denominados "urbanizadores piratas", los cuales lideraron la comercialización y ocupación de tierras en zonas periféricas de la ciudad. En el proceso de consolidación de estos barrios ha tenido un papel muy importante la organización comunitaria, con una destacada participación de los jóvenes, en la lucha por la reivindicación de los derechos de sus comunidades a la ciudad y a la vivienda, al igual que a la vida ante las numerosas víctimas de la denominada "limpieza social"4 (Gómez, 2013). En este contexto de problemas complejos, pero también de lucha y resistencia, en los barrios surgidos de este proceso de urbanización informal se han gestado propuestas de organización popular entre las cuales se ha destacado el barrio Potosí en la localidad $^{5}$ de Ciudad Bolívar, en Bogotá, lugar en el que se decidió realizar la experiencia descrita. A partir de una apuesta educativa basada en los principios de la educación popular, un grupo de profesores y estudiantes se instaló en esta zona de la ciudad para realizar trabajo comunitario, teniendo como uno de sus objetivos principales la organización barrial, esto dio origen al Instituto Cerros del Sur (Ices). En esta institución educativa se han formado no solamente líderes comunitarios sino también licenciados y profesionales que continúan trabajando por su comunidad (Díaz y Saboyá, 2014).

\footnotetext{
4 "[...] fenómeno fundamentalmente urbano y dirigido contra un espectro específico de personas que tienen en común el pertenecer a sectores sociales marginados y asumir comportamientos rechazados y considerados peligrosos por los agresores." (Rojas, 1996, p. 24).

5 Las localidades son unidades político administrativas en las que se divide Bogotá, con un total de 20, de las cuales una es rural y las demás urbanas.
} 
El acercamiento a este proyecto educativo y a la comunidad del barrio ha sido posible por conducto del programa de responsabilidad social Vidas Móviles de la Pontificia Universidad Javeriana ${ }^{6}$. Es así como mediante un taller y entrevistas semiestructuradas con madres, lideresas comunitarias, profesores, y un taller con niños estudiantes del Ices, se indagó sobre cuáles son sus percepciones respecto a los derechos de los niños y las niñas en relación con su hábitat ${ }^{7}$.

Las actividades

Con el apoyo del programa Vidas Móviles, se realizó un taller con madres participantes en su programa Madres Gestantes y Lactantes. En total se contó con la participación de 10 mujeres, quienes tienen hijos en edades en primera infancia e infancia. El taller se realizó en el mes de septiembre de 2016, con el fin de indagar la percepción que tenían las madres asistentes respecto a la relación entre las condiciones del hábitat y el disfrute de los derechos de la infancia, con énfasis en el tema del cuidado de los niños y las niñas. La conversación se planteó en relación con la casa, el barrio y la ciudad.

De manera complementaria, se realizaron entrevistas semiestructuradas con dos lideresas comunitarias con el ánimo de conocer sobre las organizaciones tanto gubernamentales como no gubernamentales que trabajan con la infancia en el barrio Potosí. Las conversaciones tuvieron como eje los derechos de la infancia y las actuaciones de las organizaciones presentes en el barrio. Estas entrevistas se realizaron de manera paralela al taller realizado con las madres.

En el mes de octubre de 2016 se realizó un taller con 10 niños con edades entre los 10 y 12 años, estudiantes del Ices, para conversar sobre su percepción de su vida en el barrio y a partir de ello identificar los factores del mismo que inciden en la vulneración de sus derechos. La dinámica se

\footnotetext{
6 Javesalud-Vidas Móviles es una iniciativa surgida en la Pontificia Universidad Javeriana que pretende acompañar, orientar y atender de manera integral a población en situación de desplazamiento forzado y a población en condiciones de vulnerabilidad que estén ubicadas en la localidad de Ciudad Bolívar, Bogotá, D.C. (véase Pontificia Universidad Javeriana, s.f.).
}

desarrolló a partir de la escritura de un cuento, el cual podían acompañar con dibujos. Cada niño participante leyó su texto ante el grupo y atendió los comentarios o preguntas de sus pares.

Finalmente, en el mes de noviembre de 2016, se entrevistaron dos profesores del Ices, muy vinculados a la historia del barrio, sobre los temas tratados con las lideresas y sobre los resultados de los talleres con las madres y los niños y niñas.

\section{Los resultados}

El taller con las madres

Los resultados que a continuación se presentan corresponden a los talleres realizados con las madres para indagar su percepción respecto a la relación entre las condiciones del hábitat y el disfrute de los derechos de la infancia, con énfasis en el tema del cuidado de los niños y las niñas. Las madres asistentes coincidieron en opinar sobre los riesgos que existen para sus hijos al interior de sus viviendas debido a las condiciones deficitarias que se presentan en las mismas. Una de las condiciones que genera mayor preocupación es la presencia de humedad, por cuanto genera problemas de salud para los miembros del hogar y más aún para los niños y niñas en primera infancia. También, se manifestaron sobre las limitaciones que supone el hecho de vivir en viviendas de alquiler y la poca disponibilidad de opciones recreativas en el barrio, como lo manifestó una madre de dos niños menores de 5 años:

Bueno, en la casa cuando uno vive en arriendo y las adecuaciones de la casa no son las mejores para los niños. La otra, en el barrio, por ejemplo, no hay muchas recreaciones para los niños. [...] Entonces, y la inseguridad del barrio, porque llevarlos a los parques a veces es inseguro. (O., madre de dos hijos menores de 5 años).

Debido a esa alta percepción de riesgo que manifestaron las madres participantes en el taller, todas afirmaron preferir dedicarse al cuidado de sus hijos pese a las limitaciones económicas en sus hogares. De otra parte, basan esta decisión en la falta de apoyo de personas de confianza para asumir esa labor en su ausencia, así como en los problemas 
con los servicios de cuidado. Sobre este último asunto, su preocupación se centra en dos aspectos: la baja cobertura de servicios de cuidado de bajo costo o gratuito y la deficiente calidad de los que se dispone en su barrio. Para el caso específico de la primera infancia, se cuenta con dos tipos de instituciones como son los Hogares de Bienestar Familiar (Hobis), programa de Madres Comunitarias, a cargo del Instituto Colombiano de Bienestar Familiar (ICBF) y los jardines infantiles de la Secretaría Distrital de Integración Social (SDIS). Todas las madres participantes manifestaron su inconformidad y desconfianza con el servicio brindado por los Hobis, pues desde su punto de vista no cuentan con instalaciones apropiadas ni personas capacitadas para prestar el servicio.

De otra parte, dos de las madres participantes en el taller consideran que el servicio de los jardines infantiles a cargo de la SDIS es de muy buena calidad, pero las demás asistentes no sabían de su existencia. Quienes lo conocían, sin embargo, comentaron que el único disponible queda lejos del lugar en el que viven. También señalaron como problemático el horario del servicio, razón por la cual incluso prefieren dejar sus hijos encerrados cuando deben salir a realizar alguna labor fuera del hogar, como lo manifestó una madre de dos niños de 6 y 8 años:

Sí, hay diurnos pero de 8 (de la mañana) a 5 (de la tarde). Y por ejemplo si uno consigue un trabajo en el centro mínimo se tiene que ir dos horas antes. Entonces si entra uno a las 8 de la mañana tiene que salir a las 6 de la mañana, ¿y de 6 a 8, quién le cuida a uno el niño? Entonces le toca a uno pagar por aparte para que por favor le lleven a uno el niño al jardín. Ahí ya es un gasto, toca pagar $\$ 1.000$ o $\$ 2.000$ para que le lleven a uno el niño al jardín. (A., madre de dos hijos de 6 y 8 años).

Lo expresado por las madres demuestra que desde su percepción las condiciones de habitabilidad en la vivienda, en el barrio y en la ciudad están altamente asociadas al del cuidado de los NNA. Por lo tanto, la mejor opción para brindar mayor seguridad a sus hijos, en su opinión, es ocuparse directamente de su cuidado considerando las dificultades para disponer de apoyo y las condiciones en las que viven. Esta es una situación que se vuelve más complicada en la medida en que crecen, específicamente desde los 6 años. Al entrar al colegio a realizar sus estudios de niveles primaria y secundaria generalmente están ocupados solo media jornada, esto aumenta el tiempo que deben permanecer sin cuidado de un adulto cuando sus padres o tutores deben salir a trabajar.

\section{El taller con los niños}

El taller fue realizado con la participación un grupo de 12 niñas y niños con edades entre 10 y 12 años en el barrio Potosí, estudiantes en el Ices, en el cual se indagó sobre su percepción en relación con su vida en el barrio e identificar los factores del mismo que inciden en la vulneración de sus derechos para analizar. Cabe destacar que hubo consenso de los niños y las niñas participantes al reconocer el aumento de la seguridad como una necesidad prioritaria en su barrio, por encima de los parques, asociada a una mayor presencia de la Policía. Mediante un ejercicio para expresar sus gustos y temores en su barrio, a través de la escritura de un breve cuento, manifestaron su alta sensación de inseguridad:

Había una vez un niño que era muy triste porque no se sentía feliz en su barrio porque le decían que el barrio era inseguro que mataban mucho. Un día el niño se propuso que debía pensar cosas buenas del barrio y no meterse donde no debe. (L., 10 años)

Había una vez un niño muy triste porque en la cuadra de él había mucha mala influencia y entonces la mamá no lo dejaba salir y entonces el niño se aburrió mucho. Entonces un día el niño se salió de la casa y hubo un enfrentamiento y al niño lo hirieron entonces a la mamá le tocó irse para el hospital, el niño quedó en coma y no reconoció a nadie. (W., 10 años)

Algunos manifestaron sentirse seguros solamente en sus casas y otros, además, en sus alrededores:

Había una vez un niño que se llamaba $D$., o sea yo. Me gusta jugar futbol con mis amigos en Arborizadora Alta y también en mi casa. Arborizadora Alta 
es un lugar muy chévere y un poco peligroso y en lugares que tengo confianza es en mi casa y en lugares que no tengo confianza es en la cuadra de un amigo. Mi casa es muy linda tengo muchas cosas, juego mucho y eso me hace feliz. Cambiaría el peligro por la paz en mi barrio para vivir mejor. (D., 11 años)

Había una vez una niña que llegó (al barrio) hace 5 meses del norte. Al principio que llegué a este barrio me sentía insegura porque dicen que el sur es más inseguro, pero cuando llegué a mi colegio me empecé a sentir segura y feliz. Pero el 31 de octubre dijeron que habían matado a un señor y a un niño de 2 años. Yo me siento segura en mi casa o en la de mi tía. Aquí dicen que hay gente muy mala y también muy buena. Me gusta mucho cantar y estar con mi familia e ir a Boyacá. (N., 10 años)

En sus palabras es evidente el temor que sienten de andar solos por su barrio debido a los hechos violentos que suceden y que ellos conocen por información directa o por sus padres. Esto limi-

ta su autonomía para movilizarse, aunque también abundan los casos de NNA totalmente autónomos cuando sus padres no pueden cuidarlos (por estar todo el día trabajando lejos de sus hogares). Entonces, los NNA deben ir y regresar solos de la escuela e incluso asumir las responsabilidades de hacer otras labores fuera de sus casas por órdenes de sus padres durante su ausencia.

\section{Las entrevistas con las lideresas}

Las entrevistas fueron realizadas a dos mujeres lideresas en su comunidad. Una de ellas vinculada con el programa Vidas Móviles y la otra con la ONG Visión Mundial Colombia. Las preguntas se enfocaron en los derechos de los NNA, los que están en condición de vulnerabilidad y las acciones desde las instituciones públicas al respecto en su barrio. En el caso de la labor de Visión Mundial, la lideresa entrevistada destacó el trabajo que se realiza en la divulgación y concientización de los derechos que tienen los NNA. De otra parte, también sobre el trabajo para garantizar una buena nutrición de niños y niñas hasta los 7 años de edad. Las mujeres que trabajan con esta organización en el barrio lo hacen como voluntarias y son capacitadas para liderar labores con los NNA, quienes son escogidos según sus condiciones de vulnerabilidad. Sin embargo, hay limitaciones presupuestales que impiden la continuidad de algunos programas.

Pero esta organización no atiende el tema del cuidado de los NNA, el cual se presume en cabeza de las familias e instituciones estatales, estas últimas solo hasta la primera infancia. A partir de la infancia y en la adolescencia no hay apoyo para su cuidado, razón por la cual cuando los NNA son hijos de madres cabeza de hogar y si no cuentan con un familiar adulto que se haga cargo cuando ellas deben ausentarse, quedan a su suerte. Generalmente, si se trata de varios hermanos, el rol de cuidador lo asume el mayor. Las situaciones de riesgo que significa el que los niños y las niñas deban preparar o calentar sus alimentos y, en general, de accidentalidad asociada al estar solos sin cuidado de adultos, se incrementan cuando habitan en viviendas que comparten con otros hogares, algo frecuente en los asentamientos de origen informal, como lo señala la lideresa vinculada a Visión Mundial:

Cuando viven en una casa en la cual alquilan más apartamentos hay condiciones de riesgo gigantescas, ¿Por qué?... por acá pues la mayoría viven así, en un piso son cuatro o cinco familias independientes, entonces pues no todas las familias tienen la misma cultura, no todas las familias tienen ese mismo respeto. No debe faltar que quede por ahí un señor solo y se dé un abuso tanto físico como psicológico con los niños, porque pues no todas las veces es algo físico sino también psicológico de decirles: "a ustedes nadie los quiere, ustedes son unos brutos, usted eche para allá que usted no es de aquí de mi pieza". Entonces todo eso es un factor de riesgo alto. Otro: no hay las condiciones adecuadas, que tiene un niño de 2 o 3 añitos que no conoce los límites de las escaleras; los hermanitos que quedan en cuidado de ellos, el hecho de calentar la comida, manejar un cuchillo. Acá no tenemos la cultura de decir: "es que aquí bajo llave voy a dejar lo que es el cloro, el jabón y el raticida. No va a pasar, porque la cocina qué es, es una mesita con la estufa y pa' fuera. Entonces sí hay mucho, mucho riesgo.

Pero esta es una situación frecuente en los hogares con un solo jefe, generalmente mujeres, 
quienes deben resolver el sostenimiento económico del hogar y asumir el riesgo de dejar a sus hijos solos como lo indica la lideresa vinculada a Vidas Móviles:

La mamá se tiene que ir, entonces deja los niños encerrados, los niños se quedan solos, o se quedan con el hermano o hermanita mayor, que ya salen y se van jugando. Hace mucho tiempo nos pasó el caso, cuando estábamos arriba, de que una señora tenía que irse a trabajar. Ella se iba a trabajar, tenía dos niños pequeños: una niña grandecita y otro más grandecito. Los niños se pusieron a jugar, cuando los niños grandes no encontraban a los niños pequeños, cuando la señora llegó desesperada, y cuando empezaron a buscar, y ella se fue por un lugar del patio, cuando resulta que los niños se habían metido en una caneca, la más grandecita metió al niño en la caneca, y ella se metió y tapó la caneca. Cuando la señora sintió que algo se movía, levantó la caneca y vio al bebé muerto, y a la niña agonizando, no alcanzó a llegar al hospital.

Por lo expuesto, el tema del cuidado de los NNA debe revisarse en el contexto de la familia y de las condiciones en las que vive, pues justamente es la familia la que le da el soporte básico y desde el cual se necesita acompañamiento. Aun cuando en la propuesta del trabajo del ICBF se resalta la importancia del trabajo con la familia, hay críticas a su labor de cara a las circunstancias que se viven en varios barrios de origen informal de Ciudad Bolívar:

La verdad yo siempre, la gente dice Bienestar Familiar, yo siempre he dicho malestar familiar. Hay muchas cosas de Bienestar Familiar con las cuales no he estado muy de acuerdo, porque siempre están muy pendientes como del niño, y que por qué el niño es dejado solo, por qué el niño es maltratado, por qué al niño la mamá lo dejó solo en la casa con los otros hermanitos. Pero lo que no ven ellos es el entorno en la familia, y no ven el porqué de eso, entonces siempre en vez de terminar organizando la familia, la termina destruyendo. Desde mi propia experiencia he visto muchos casos. Tenemos uno pendiente de los Góngora, que eran una familia, ella tenía que trabajar, el papá tenía que trabajar, el papá era alcohólico, tenían sus problemas familiares, maltrato entre la mamá y el papá, pero eran cosas entre ellos, por cosas de la mamá, y pues los niños permanecían mucho tiempo solos, y el Bienestar Familiar se los llevó, todos los cuatro, se los quitaron a todos. Esos niños han sufrido mucho, todavía me llaman; el hogar se desintegró, el señor se fue, la mamá se fue y dejaron los niños totalmente abandonados. (S.C.)

Este testimonio deja en evidencia la importancia de entender en toda su complejidad la garantía de los derechos de los NNA. Es limitado prestar unos servicios de cuidado sin considerar las actividades de los padres o separar a los NNA de sus familias porque no los cuidan adecuadamente, desconociendo las causas, para que queden en situación de abandono.

\section{Entrevistas con los docentes}

Se conversó con dos docentes del Ices que conocen el barrio desde sus inicios y a su comunidad, a la cual han contribuido a formar y fortalecer. Se les propuso como temáticas la preocupación por la inseguridad en el barrio manifestada por los niños y las niñas que participaron en el taller, el temor de las madres a dejar solos a sus hijos o en jardines infantiles si salen a trabajar y las percepciones de las lideresas sobre las acciones de organizaciones tanto del públicas como no gubernamentales.

En lo que concierne a la preocupación manifestada por los niños y las niñas respecto a la violencia en su barrio, es de conocimiento de los habitantes del barrio que se asocia a la presencia de microtráfico de sustancias psicoactivas, pandillas, paramilitarismo y guerrilla. Así ha sido reconocido en el caso de la localidad de Ciudad Bolívar y su área colindante con el municipio de Soacha (Pérez, 2007). El atroz fenómeno de la "limpieza social" ha sido una estrategia de control territorial mediante la cual han sido asesinados jóvenes y líderes comunitarios de forma selectiva y se ha impuesto un orden al servicio de unos intereses determinados (Gómez, 2013). Lamentablemente, esta práctica ha adquirido cierto nivel de legitimidad para los habitantes de algunos de los barrios de origen informal, quienes lo consideran una manera de resolver situaciones problemáticas para la comunidad o para intereses particulares. Como comenta en una entrevista uno de los profesores del Ices: 
El tema de la limpieza social, que es un tema tan recurrente acá, que son pues asesinatos selectivos, a lo que se llama limpieza social. Ese tema de los asesinatos de los jóvenes parece ser que para muchos es la solución a esta problemática de los chicos que están muy, como acá les llamamos, "calentados", es decir, que ya tienen problemas muy fuertes de robos y de consumo de sustancias psicotrópicas. Hay mucha gente del barrio que cree que matarlos es la mejor solución, pero llevan matando muchos años a jóvenes acá y el problema se perpetúa. Y el problema se perpetúa por esto, porque nuestros niños desde muy tempranas edades ven, perciben, sienten o huelen, tocan lo que es Ciudad Bolívar, o lo que ha sido Ciudad Bolívar históricamente. (A. T.)

Pero no se trata de una problemática disociada del tema del cuidado infantil, pues el hecho del tiempo que muchos NNA deben permanecer solos mientras sus padres trabajan propicia que se involucren en situaciones inconvenientes para sus vidas.

Ese proceso de marginalización lastimosamente desemboca en eso, es un problema estructural. Por ejemplo, yo tampoco creo que los pobres son pobres porque quieren, como dicen muchas personas que piensan que porque hay una o dos niñas embarazadas en el colegio esas chicas son las que tienen a la localidad así; o el señor que se toma ${ }^{7}$ lo del mercado, que no son todos nuestros papitos. Entonces toman a esas personas como ejemplo de que así es, son pobres porque quieren, cuando el problema está en que nuestros papitos y nuestras mamitas se levantan muy temprano por la mañana para ir a trabajar, dejando a sus hijos solos, para medio conseguir lo del vivir diario. Parecemos gallinitas, conseguimos lo del diario, entonces no tenemos espacios para sacar a nuestros chicos a los parques, al cine, para comprarles libros, juguetes, para comprarles cosas deportivas. Entonces creo que el problema radica en eso, en que hay toda una estructura social para que se mantenga esa línea en la que unos que son privilegiados sigan manteniendo ese tipo de privilegio, y los que no lo han sido

\footnotetext{
7 Hace referencia a destinar el dinero para el consumo de bebidas alcohólicas.
}

o no lo han tenido por desgracia divina mantengan siendo pobres. Yo creo que es un tema de estructura social. (A. T.)

Adicional a lo expuesto, el trabajo que se hace con la comunidad para cambiar los patrones de comportamiento hacia los NNA no cuenta con un soporte suficiente desde las políticas públicas. Como señala otro de los profesores del Ices:

Frente a la vulneración de los derechos de los niños trabajamos en crear conciencia del entorno para superar la violencia familiar y el desinterés en el futuro. Una causa fundamental se encuentra en las limitadas oportunidades que tienen los padres de familia a nivel laboral, lo cual limita sus posibilidades de sostenimiento de sus hijos. La política pública no atiende el centro del problema que es la familia como responsable de sostener y educar a los NNA. (L. O.)

Ahora, la percepción de inseguridad por parte de los niños y niñas que participaron en el taller y su posible solución con el aumento de la presencia de la Policía, también es compartida por los adultos quienes influyen en sus opiniones. De alguna manera, es una situación que responde a la estigmatización de la localidad de Ciudad Bolívar:

[...] la opinión de los niños sobre la necesidad de más Policía en el barrio para mejorar la seguridad es resultado de los medios de comunicación que propagan el miedo. Pero el problema no es de armas. El asunto es cómo resolver el problema, lo cual requiere un trabajo conjunto con la Policía en un marco de responsabilidades compartidas en lo político y lo social. El problema es de todos y requiere procesos de organización, porque se financia la guerra y no los territorios. (L. O.)

Este último comentario deja nuevamente sobre la mesa la importancia del reconocimiento de lo que sucede en las diferentes partes de una ciudad. Las condiciones sociales, económicas y culturales están mediadas por los procesos en los cuales se construye el territorio en donde habitan las personas. En este sentido, las diferencias existentes entre los asentamientos de origen formal y los informales 
tienen incidencia sobre la vida de las personas que los habitan. Como señala Rodríguez:

Hablar de territorio implica articular la sociedad porque su relación directa se expresa a través del concepto de territorialidad como pertenencia territorial supeditada a procesos de identificación y de representación colectiva e individual que generalmente desconoce las fronteras políticas o administrativas y no aduce exclusivamente la apropiación espacial estatal o ligada a un grupo de poder. $(2010$, p. 1)

En este sentido, una lectura desde el territorio, en procesos como el que sucede en los asentamientos de origen informal, demanda un reconocimiento de sus particularidades para un diseño y aplicación de políticas públicas adecuadas.

\section{Discusión}

Sobre el derecho al cuidado

Las reflexiones recientes en torno del cuidado lo postulan como un bien público y, por ende, de responsabilidad colectiva. En este sentido no se trata de una responsabilidad privada a cargo de la familia, sino que le corresponde al Estado tanto regular como proveer este servicio, pues no se puede delegar exclusivamente en el mercado dado que aumentaría las asimetrías presentes en la sociedad (Faur, 2014). Pero en un contexto urbano en el que prevalece un sentido del cuidado como disciplinador y represivo, es necesario evolucionar a un concepto social y político basado en la libertad, para la atención democrática a la niñez y la crianza como una expresión colectiva y no individual (Guendel, 2012).

En Colombia, según la Constitución Política de 1991 artículo 44, los derechos de los NNA tienen carácter de prevalencia respecto a los derechos de las demás personas. Lo anterior al considerar el especial grado de protección que requieren por sus condiciones de vulnerabilidad y su estado de indefensión, al igual que la atención especial con que se debe salvaguardar su proceso de desarrollo y formación. En este contexto, los NNA no deben cumplir obligaciones como condición para el ejercicio de sus derechos humanos o para el acceso a los servicios estatales que deben garantizar esos derechos (Presidencia de la República de Colombia, 2007).

Con la Ley 1098 de 2006 fue aprobado el Código de la Infancia y Adolescencia, considerado como un avance sustantivo en lo que a temas sobre derechos de la niñez se refiere, basado en un enfoque universal como es la protección integral. Se enuncian como esenciales los principios del interés superior, la prevalencia de derechos y la corresponsabilidad entre el Estado, la sociedad y la familia para la garantía de sus derechos (Codia, 2011).

No obstante, el país, desde la década de 1970, ha sido reconocido en el contexto latinoamericano por los servicios ofrecidos a la primera infancia. Uno de sus programas destacados ha sido el de los Hogares Comunitarios a cargo del ICBF que desde 1987 ha atendido a poblaciones urbanas, semiurbanas y rurales en situación de pobreza severa y debajo del nivel de pobreza, con prioridad para los hogares encabezados por mujeres, familias victimas del desplazamiento forzado por el conflicto armado interno y familias indígenas (Unicef, 2008).

En relación con este programa del ICBF, en el caso de Bogotá se debe destacar que es en los barrios de origen informal que se desarrollaron en las localidades Ciudad Bolívar y Usme, a principios de la década de 1980, en los que las mujeres se organizaron para atender el cuidado de los niños y las niñas. Así, con recursos obtenidos mediante el apoyo de la comunidad, se establecieron pequeños jardines infantiles. Pero ante la imposibilidad de sostenerlos las mujeres decidieron demandar del Estado, y específicamente del ICBF, y del Departamento Administrativo de Bienestar Social (DABS) ${ }^{8}$ el reconocimiento y financiamiento necesarios para la continuidad del servicio. Aun cuando lograron financiamiento, no obtuvieron el reconocimiento de su labor en el cuidado de la infancia ni una remuneración justa para su trabajo. Al contrario, en buena medida se mantuvo el "voluntariado femenino" con el que se iniciaron los jardines infantiles. Así, los programas más fuertes de atención a

\footnotetext{
8 Institución distrital, ahora denominada Secretaría Distrital de Integración Social (SDIS).
} 
la infancia como los Hobis ${ }^{9}$ del ICBF y las Casas Vecinales del DABS conservaron la labor con muy baja remuneración de las mujeres que iniciaron la atención a la infancia (García, 2013). Estos dos servicios continúan funcionando en la actualidad, especialmente localizados en los barrios con mayores niveles de pobreza. No obstante, cabe destacar que la administración distrital ha realizado un esfuerzo importante por mejorar la prestación del servicio contratando docentes capacitados para el cuidado y formación de los niños y las niñas a nivel preescolar en los ahora denominados simplemente jardines infantiles.

Las opiniones de las madres que participaron en el taller y de las lideresas denotan una diferencia de calidad entre ambos tipos de servicio. Se reconoce que los Hobis tienen baja calidad, debido a que no cuentan con la infraestructura adecuada y los cuidadores tampoco tienen la capacitación suficiente para garantizar una buena atención de los niños y las niñas. En el caso de los jardines infantiles distritales se reconoce una mejor calidad, pero baja cobertura, tanto espacial como temporal, lo que dificulta a las madres trabajadoras acceder a sus servicios.

Lo expuesto demuestra que el tema del cuidado de los niños y las niñas de hogares en situación de pobreza, los cuales habitan en cantidad importante en barrios de origen informal, demanda una atención diferente a la que se presta en la ciudad formal. Es decir, las condiciones de vida de los hogares están inevitablemente mediadas por el territorio en la medida en que de la localización depende el acceso a lugares de trabajo y a servicios urbanos. Como manifiestan las madres entrevistadas, los trabajos a los que pueden acceder generalmente quedan muy lejos de donde viven y la oferta de los jardines infantiles públicos cerca a sus viviendas es insuficiente e ineficiente. En unos casos por mala calidad del servicio y en otros porque quedan lejos, lo que dificulta el acceso. Sumado a lo anterior, se

\footnotetext{
9 Los Hogares de Bienestar Familiar fueron la propuesta de jardines infantiles del ICBF para los barrios con población de bajos ingresos, entre estos los de origen informal. Estos jardines funcionaban en la casa de la madre comunitaria y el ICBF aportaba alimentos en un principio y luego material pedagógico y enseres. Aún siguen funcionando con este esquema (ICBF, 2017).
}

tiene que los horarios de servicio no son adecuados respecto a los de los padres trabajadores quienes deben sumar a las horas de jornada laboral las que gastan movilizándose en la ciudad. Esto da como resultado un desfase de tres o cuatro horas respecto al servicio, situación que deben resolver los padres. Cuando no cuentan con apoyo familiar las decisiones van desde el pago a vecinos, que no garantizan un buen cuidado, o dejar los niños encerrados. En los hogares con jefatura de padre y madre se tiene la opción de que alguno de los dos (generalmente la madre) se quede en casa cuidando a los niños. Pero cuando solamente hay un jefe de hogar y no hay apoyo familiar para el cuidado, las condiciones de riesgo para los niños y las niñas son mayores cuando su progenitor debe irse a trabajar.

En consecuencia, es posible considerar la segregación socioespacial urbana como un agente que aumenta las asimetrías presentes en la calidad del cuidado de la infancia en la ciudad y, por ende, vulnera este derecho. Lo anterior si se considera que las áreas urbanas en las cuales se concentran hogares en situación de pobreza ${ }^{10}$ generalmente están en desventaja en cuanto al acceso a los lugares de oferta de empleo y a los servicios urbanos con respecto a los hogares que no están en esa situación y habitan en áreas con acceso a los mismos. Como señala Torres (2016), las condiciones del vecindario, entre las cuales la localización puede implicar un factor discriminante en la calidad del trabajo y de acceso a la educación, afectan tanto presente como futuro de los individuos que lo habitan. Por lo tanto, la segregación se constituye como la expresión espacial de las desigualdades económicas y sociales, generando la concentración de comunidades cada vez más homogéneas cuyas características acentúan las distancias entre pobres segregados y ricos.

\footnotetext{
10 "La pobreza afecta más y con mayor profundidad a la infancia. Si comparamos las proporciones de pobreza infantil con las resultantes en la población general, podemos apreciar cómo este fenómeno afecta de mayor manera a niños y niñas que a los adultos: mientras que la pobreza monetaria general de los hogares bogotanos fue de $15,76 \%$ en 2014; la pobreza en hogares donde viven niños/as fue casi 10 puntos porcentuales mayor $(24,46 \%)$. De igual manera sucedió con la pobreza extrema, mientras que en general fue de $4,15 \%$, en hogares con población infantil fue de 4,60\%.". (Minujin, 2016, p. 4)
} 
Sobre el derecho de la infancia a su autonomía en la ciudad

La calle en la ciudad constituye un espacio clave para desarrollar la autonomía, propiciar el encuentro y la socialización de las personas. Es el lugar en el que los miembros de una comunidad urbana pueden desarrollar lazos que generan sentimientos de pertenencia hacia el territorio que habitan. Pero en el mundo contemporáneo la aparición de los hogares autónomos ha desplazado lo colectivo para entronizar la individualidad y la calle ha ido perdiendo su esencia como lugar de encuentro (Tonucci, 2005; González, 2012). En este contexto, entre los más afectados están los NNA, pues la calle se ha convertido en el lugar del tráfico automotriz, inseguro para ellos, destinándoles a cambio espacios artificiales, cerrados, aislados y controlados por los adultos.

Sumado a lo anterior, el barrio también ha perdido su papel como lugar privilegiado para el desarrollo de la infancia, pues era donde se podía jugar al aire libre y relacionarse con otros, permitiendo que los NNA interactuaran con el medioambiente sin el control de los adultos (Sanz, 2014). Estas circunstancias repercuten de manera negativa en la salud de los NNA, lo que para algunos convoca al debate sobre el diseño urbano y el espacio público (Muntañola, Saura y Méndezes, 2013).

No obstante, la situación de NNA en los barrios de origen informal es diferente, dado que el proceso de origen de estos barrios y su consolidación difieren ampliamente de lo que sucede en la ciudad formal. En este contexto, los NNA crecen en medio de dos circunstancias: la ausencia de un espacio público que les permita disfrutar del juego, del encuentro con otros de una manera segura y adecuada; y de otra parte, muchos se ven obligados desde muy corta edad a asumir la autonomía de su propio cuidado y en muchos casos de hermanos menores.

El espacio público suele ser escaso e infradotado; además, en muchas ocasiones es lugar de confrontación, especialmente por parte de los adolescentes, quienes terminan desplazando a los más pequeños (Caquimbo, Ceballos y López, 2016). Adicionalmente, se presentan problemas de inseguridad, pues son sectores urbanos en los cuales existe microtráfico de sustancias psicoactivas y consumo de las mismas, lo cual suele concentrarse en los espacios públicos.

En cuanto a la autonomía obligada de muchos NNA desde muy temprana edad, esta es consecuencia de las dificultades que tienen sus padres para cuidarlos. Como se señalaba en el aparte previo de este artículo, no resulta sencillo para muchos padres resolver el tema del cuidado de sus hijos en su ausencia mientras trabajan, lo que obliga a que los NNA deban ir y regresar solos de la escuela y en ocasiones preparar sus alimentos y cuidar de hermanos más pequeños.

Ahora, la percepción de inseguridad por parte de los niños y niñas que participaron en el taller y su posible solución con el aumento de la presencia de la Policía también es compartida por los adultos, quienes influyen en sus opiniones. De alguna manera es una situación que responde a la estigmatización de la localidad de Ciudad Bolívar. Este es un asunto que se reconoce como asociado a la violación sistemática de los derechos humanos de sus habitantes, especialmente de la población joven: estigmatización, señalamiento, genocidio, desaparición y ejecuciones extrajudiciales (Gómez, 2013). Es la consecuente violencia simbólica que recae en los barrios en los que habitan personas en situación de pobreza; identidades deterioradas de carácter colectivo que se imponen sobre ciertos barrios de la ciudad considerados reductos de delincuencia y pobreza (Cornejo, 2014). Los NNA son testigos y en ocasiones víctimas tanto de la violencia asociada a hechos delictuales como a la simbólica manifiesta en la estigmatización, lo cual les genera temor al igual que a sus padres, limitando su derecho a disfrutar con autonomía segura su territorio. En este sentido se puede plantear que la estigmatización del territorio en los barrios de origen informal se constituye en un elemento de vulneración de los derechos de los NNA.

\section{A manera de conclusión}

Al inicio de este artículo se expusieron las consideraciones que sobre la situación de la infancia en la ciudad han sido abordadas por varios investigadores. Los estudios referidos se han centrado en la autonomía de los NNA en la ciudad y su derecho a participar en las decisiones de la misma. Pero, 
respecto a la situación de los NNA que viven en condición de pobreza, y especialmente de quienes habitan en las áreas de las ciudades que han tenido un origen informal, se ha encontrado que los estudios al respecto son escasos.

Es por ello que se propuso un estudio exploratorio, el cual partió en una primera fase de la revisión del estado del arte sobre los derechos de la infancia y su relación con la ciudad. En la segunda fase, expuesta en el presente artículo, se ha presentado el trabajo realizado desde la percepción de quienes tienen relación con la temática para tejer entre lo que dicen los actores involucrados y lo hallado en la revisión del estado del arte. Esta fase se centra en los niños y las niñas hasta la infancia, madres cuidadoras, líderes comunitarias y docentes en el barrio de origen informal Potosí, localizado en la localidad Ciudad Bolívar de Bogotá. Se propuso como objetivo identificar las condiciones del hábitat que interfieren con el disfrute de sus derechos y formular hipótesis de trabajo que serán abordadas en la fase final del estudio.

Al respecto, la primera condición identificada en relación con las condiciones físico-espaciales en las cuales viven los NNA se deriva de lo hallado en la literatura: el hacinamiento como condición de la habitabilidad que expone a los NNA a problemas de salud física y mental. En la salud física por cuanto afecta su salud respiratoria y en la mental porque los expone a sentimientos depresivos, mayor violencia intrafamiliar y al abuso sexual (Feres y Mancero, 2001; Ceballos et al., 2014). También es una condición que los deja en desventaja en los procesos de aprendizaje respecto a los NNA que habitan en condiciones opuestas, dado que el hacinamiento dificulta la concentración necesaria para el estudio en casa (Kaztman, 2011). Así, el hacinamiento en la vivienda, que se presenta con alta frecuencia en los asentamientos de origen informal, vulnera el derecho de los NNA a vivir en condiciones adecuadas, exponiéndolos a riesgos para su salud física y mental, y por ende para su normal desarrollo.

Como una segunda condición se ha identificado la segregación urbana como factor que vulnera el derecho de los NNA al cuidado. Lo anterior, pues se da la concentración de hogares pobres en comunidades cada vez más homogéneas, generalmente en zonas de periferia urbana, lo cual dificulta a sus padres el acceso a los lugares de empleo y a los servicios de la ciudad. Esto conlleva en muchos casos a que los padres deban dejarlos solos mientras van a sus lugares de trabajo, los cuales generalmente quedan muy lejos de sus viviendas, y los servicios públicos de cuidado son insuficientes o ineficientes. Algunos optan por dejarlos encerrados o bien con autonomía para ir y regresar solos de la escuela, preparar sus alimentos y en algunos casos hacerse cargo además de hermanos menores.

Por último, como tercera condición se ha identificado la estigmatización como forma de violencia simbólica que vulnera el derecho de los NNA a disfrutar el lugar en que habitan. Esto ha generado tanto una mirada externa como interna muy negativa sobre las personas en condición de pobreza que habitan en barrios de origen informal. Se les asocia con delincuencia y factores de inseguridad, ampliamente difundido por los medios de comunicación, lo que conlleva a que los NNA se vean afectados en su percepción de su entorno inmediato y asocien la existencia de condiciones inseguras con la necesidad de más presencia policial. Si bien se podría afirmar que es la inseguridad de origen delictivo la que afecta su derecho a la autonomía en su territorio, se identifica que es la legitimización social del uso de la violencia como forma de resolver los problemas presentes en un territorio estigmatizado como problemático para la sociedad lo que lleva a tolerar y fomentar acciones violentas. De esta manera, se termina "normalizando" tanto en el territorio como en los medios de comunicación que en un barrio de origen informal sucedan asesinatos de "jóvenes problemáticos" como acciones ejemplificadoras, sin que los problemas de fondo sean resueltos y dejando a los NNA en un entorno incierto minado por el temor.

\section{Agradecimientos}

Quiero manifestar mi gratitud a las personas que me permitieron avanzar en esta etapa de mi investigación: al profesor Leónidas Ospina, uno de los fundadores el Ices; al profesor Andrey Téllez, vinculado a este proyecto pedagógico; a Sarita Castro, vinculada al proyecto social Vidas Móviles y líder comunitaria; 
a las mujeres que aceptaron participar en las entrevistas y en el taller; a los niños que participaron en el taller, especialmente por su espontaneidad y su amor por la vida. En general, a los habitantes del barrio Potosí por su generosidad y afecto.

\section{Referencias}

Auyero, J. (2010). Infancia en peligro tóxico. Experiencia y negación. Apuntes de Investigación del Cесур, 16/17, 23-38.

Campos, S. (2009). La convención sobre los derechos del niño: el cambio de paradigma y el acceso a la justicia. IIDH, 50, 351-377.

Caquimbo, S., Ceballos, O. y López, C. (2016). Espacio público, periferia urbana y derecho a la ciudad. Intervención Parque Caracolí, ciudad Bolívar. Invi, 32(89), 113-143. https://doi. org/10.4067/S0718-83582017000100113

Ceballos, O., Caicedo, J., Fernández, A. y Rincón, M. (2014). Salubridad de la vivienda informal. En: El traspatio de la ciudad. Desafíos, prácticas y recomendaciones de política pública y de capacitación frente a la vivienda informal. Bogotá: Swisscontact, Fundación Suiza de Cooperación para el Desarrollo Técnico.

Cely, R. D. (2015). Análisis de los niños, niñas y adolescentes como sujetos de derechos. Salud y Sociedad, 2(1).

Comité Operativo Distrital de Infancia y Adolescencia (Codia) (2011). La política de infancia y adolescencia en Bogotá D.C. 2011-2021. Bogotá: Alcaldía Mayor de Bogotá.

Cornejo, C. (2014). Estigma territorial como forma de violencia barrial. El caso del sector El Castillo. Invi, 27(76), 177-200. https://doi. org/10.4067/S0718-83582012000300006

Díaz, L. y Saboyá, C. (2014). La enseñanza de las matemáticas una posibilidad para fomentar relaciones democráticas (proyecto asociado a la práctica pedagógica). Proyecto de investigación presentado para optar por el título de Licenciados en Matemáticas. Universidad Pedagógica Nacional, Bogotá, Colombia.

Duarte, J. (2013). Infancias contemporáneas, medios y autoridad. Revista Latinoamericana de Ciencias Sociales, Niñez y Juventud, 11(2), 461-472.
Faur, E. (2014). El cuidado infantil en el siglo XXI. Mujeres malabaristas en una sociedad desigual. Buenos Aires: Siglo XXI.

Feres, J. y Mancero, X. (2001). El método de las necesidades básicas insatisfechas (NBI) y sus aplicaciones en América Latina. Santiago de Chile: Cepal.

García, L. (2013). El barrio popular en Bogotá en las voces de sus protagonistas. Madres comunitarias y jardineras: 1980-2011, Usme y Ciudad Bolívar. Folios, segunda época, 38, 121-140. https:// doi.org/10.17227/01234870.38folios121.140

Gómez, N. (2013). Partir de lo que somos. Bogotá: Alcaldía Mayor de Bogotá, Secretaría de Gobierno Alcaldía Local de Ciudad Bolívar, Junta Administradora Local de Ciudad Bolívar.

González, M. (2012). El derecho de la infancia a la ciudad. En: Seminario Proyectos Educativos de Movilidad. Infantil en las Ciudades. IV Encuentro de Camino Escolar. San Sebastián, España: Observatorio de la Sostenibilidad, Fundación Cristina Enea.

Guendel, L. (2012). Género e infancia y ética del cuidado. La Paz: Edobol.

Gülgönen, T. y Corona, Y. (2015). Children's perspectives on their urban environment and their appropriation of public spaces in Mexico City. Children, Youth and Environments, 25(2), 208228. Recuperado de http://www.jstor.org/ journal/chilyoutenvi https://doi.org/10.7721/ chilyoutenvi.25.2.0208

Hart, R. (1993). La participación de los niños. De la participación simbólica a la participación auténtica. Florencia: Centro Internacional de Desarrollo Infantil.

Instituto Colombiano de Bienestar Familiar (ICBF) (2017). Manual operativo de la modalidad comunitaria para la atención a la primera infancia.

Jaramillo, J. (2007). La Constitución de 1991: un análisis de sus aportes desde una perspectiva histórica. Pensamiento Jurídico, (20). Recuperado de https://revistas.unal.edu.co/index.php/ peju/article/view/38626

Kaztman, R. (2011). Infancia en América Latina: privaciones habitacionales y desarrollo de capital humano. Santiago de Chile: Naciones Unidas, Cepal, Unicef. 
Minujin, A. (2016). Bogotá, cómo vamos en infancia. Monitoreo local del bienestar y las inequidades de la infancia urbana. Bogotá: Programa Bogotá Cómo Vamos, Fundación Corona.

Muntañola, J., Saura, M. y Méndezes, S. (2013). Salud infantil y calidad urbanística de las áreas urbanas. Newsletter, 50.

Organización de Naciones Unidas (2002). Sesión especial a favor de la infancia. Recuperado de https://www.unicef.org/spanish/specialsession/ rights/

Pontificia Universidad Javeriana (s.f.). Vidas móviles. Recuperado de http://med.javeriana.edu. co/vidas moviles/

Presidencia de la República de Colombia (2007). Marco para las políticas y lineamientos para la planeación del desarrollo de la infancia y la adolescencia en el municipio. Guía para alcaldes. Bogotá: Presidencia de la República de Colombia.

Rodríguez, D. (2010). Territorio y territorialidad. Nueva categoría de análisis y desarrollo didáctico de la Geografía. Uni-Pluri/Versidad, 10(3).

Rojas, C. (1996). La violencia llamada limpieza social. Bogotá: Cinep.
Sanz, D. (2014). Infancia y espacio urbano: jugar y convivir en un barrio de El Puerto de Santa María (trabajo final del Máster Interuniversitario en Cultura de Paz, Conflictos, Educación y Derechos Humanos). Universidad de Cádiz, España.

Tarchópulos, D. y Ceballos, O. (2003). Calidad de la vivienda dirigida a los sectores de bajos ingresos en Bogotá. Bogotá: Centro Editorial Javeriano.

Tonucci, F. (2005). Citizen child: play as welfare parameter for urban life. Topoi, 24(2), 183-195. https://doi.org/10.1007/s11245-005-5054-4

Unicef (2008). Implementación a gran escala: el desarrollo de la primera infancia en América Latina. Diseñando programas exitosos y sostenibles con cobertura nacional. Washington: The Rise Institute. Recuperado de https://web. oas.org/Childhood/ES/Lists/Recursos $\% 20 \% 20$ Bibliografia/Attachments/45/46.pdf

Unicef (2009). Estado Mundial de la infancia. Edición especial. Conmemoración de los 20 años de la Convención sobre los derechos del niño. Nueva York: Unicef. https://doi. org/10.18356/1a47f99d-es 